This PDF is a selection from a published volume from the National Bureau of Economic Research

Volume Title: Analyses in the Economics of Aging

Volume Author/Editor: David A. Wise, editor

Volume Publisher: University of Chicago Press

Volume ISBN: 0-226-90286-2

Volume URL: http://www.nber.org/books/wise05-1

Publication Date: August 2005

Title: Intensive Medical Technology and the Reduction in Disability

Author: David M. Cutler

URL: http://www.nber.org/chapters/c10360 


\section{Intensive Medical Technology and the Reduction in Disability}

David M. Cutler

Substantial recent evidence shows a reduction in disability among the elderly in the United States. Manton and Gu (2001), for example, document a 25 percent decline in disability among the elderly population between 1982 and 1999 — a reduction of over 1 percent per year. Cutler (2001) shows similar measures of disability decline in a variety of different surveys. The consensus among researchers has moved toward the conclusion that the elderly are getting healthier, even as they are living longer (Freedman, Martin, and Schoeni 2002).

The major issue raised by these findings is why disability has declined. There is, of course, a scholarly interest in knowing why disability has fallen. But there are public policy reasons to care as well. Understanding disability trends is essential in making forecasts about the medical needs of the elderly population. The disabled spend seven times what the nondisabled do on medical care. Reductions in disability, if they continue, could thus have large effects on the medical burden of an aging society (Pardes et al. 1999). Feedback the other way is possible as well. To the extent that lower disability is driven by increased medical spending, changes in the medical system could influence the future health of the elderly population. Reductions in Medicare payments that reduce the growth of intensive procedure use, for example, might adversely affect the health of the aged population.

Very little is known about what factors have influenced disability trends, although there are many possibilities. Medical advance is clearly one fac-

David M. Cutler is the academic dean of the faculty of arts and sciences and a professor of economics in the Department of Economics and Kennedy School of Government at Harvard University, and a research associate of the National Bureau of Economic Research.

I am grateful to Danielle Ferry for excellent research assistance, to Alan Garber for comments, and to the National Institute on Aging grant R01 AG19805 for research support. 
tor. People who are sick receive more intensive medical care than they used to, often with the goal of reducing disability (in addition to extending life). For the purposes of this paper, I divide medical advances into major procedures such as surgery for hip problems or heart disease, and less intensive forms of therapy such as prescription medications. This is largely for data reasons; the data that I use have information on intensive procedures but not medication usage.

Beyond medical advance, some have attributed reduced disability to an increasingly educated elderly population (Freedman and Martin 2002), environmental changes such as fewer buildings with only stairs (Institute of Medicine 1997), less strenuous work when younger (Case and Deaton, chap. 6 in this volume), and increased use of technological aids to overcome potential impairment (Manton, Corder, and Stallard 1993).

In this paper, I present preliminary evidence on the role of one of these factors in explaining reductions in disability: increased medical procedure use in response to acute episodes of disease. Procedures consist largely of major surgical operations - open-heart surgery for people with cardiovascular disease and hip replacements for people with fractures or severe arthritis, for example. Use of these procedures has diffused widely, in many cases doubling or tripling over a decade, suggesting they could play a large role in improved health.

I document two facts about procedure receipt and disability change. First, I show that most of the reduction in disability is not from people having fewer disabling conditions. The share of people with a stroke, fracture, or other serious condition has increased over time. Rather, reduced disability is because fewer people who have these conditions become disabled. Since intensive medical care is most important after a person has an acute event, this suggests the potential role of increased utilization of medical services in reducing disability.

Examining specific technologies shows that receipt of intensive procedures is associated with some reduction in disability, but not an enormous amount. People with musculoskeletal problems and circulatory disease are much more likely to get surgery now than in the past, and disability for people with these conditions has fallen. But this is not a large share of the total decline. Other medical and nonmedical interventions are more important in aggregate. I speculate about what other factors might be relevant, but I do not provide conclusive evidence.

This paper is structured as follows. The first section explains the measure of disability and presents trends in disability over time. The second section divides declining disability into reduced incidence of major conditions and reduced disability for people who experience those conditions. The third section examines the role of medical technology in explaining why serious diseases are not as disabling as they used to be. The last section concludes. 


\subsection{Trends in Disability}

Disability has both a medical and a social component. ${ }^{1}$ In the broadest definition, a person is disabled if he or she cannot perform the activities usually associated with a person of that age and position in life. The expectation about what one can do clearly involves a number of different factors. A twenty-five-year-old who cannot lift a twenty-pound box would probably be classified as disabled; a seventy-year-old with the same inability, in contrast, would not.

The definition of physical needs then becomes important. What is a person supposed to be able to do? In practice, most researchers focus on basic activities associated with independent living: people are classed as disabled if they cannot perform the necessary activities needed to live on their own. These necessary activities are of two types: physical activities of daily living (ADLs) and social or cultural instrumental activities of daily living (IADLs). Activities categorized as ADLs include eating, getting into and out of bed, getting around inside, dressing, bathing, and using the toilet. Activities categorized as IADLs consist of shopping, doing laundry, doing light housework, demonstrating outdoor mobility, managing medications, managing money, getting to places out of walking distance, and preparing meals.

The definition of disability here is very strict. Disability is the very low end of the spectrum of independent living. A person who cannot climb a flight of stairs but has no difficulty getting places without stairs, for example, would not be disabled. In analyzing medical interventions, this distinction is important. Many medical interventions are designed to improve health through better higher-end functioning. The impact of these interventions may be missed with such a measure of disability. Still, the majority of research in the area examines the severe disability measure, so it is a useful starting point.

The bulk of research on disability uses data from the National LongTerm Care Survey (NLTCS). ${ }^{2}$ The NLTCS began in 1982 with a sample of the community-dwelling population. It was conducted again in 1984, 1989, 1994, and 1999. In each case, people in one wave are followed in subsequent waves, and a new sample is drawn to keep the survey nationally representative. The nearly twenty years of comparable data make the NLTCS unique in health surveys.

The NLTCS has been linked to Medicare claims records. This is important because claims records are the most reliable source of information on

1. See Pope and Tarlov (1991) and Verbrugge and Jett (1994) for discussion.

2. Information on the NLTCS can be found on the Duke University web site, www.cds.duke .edu. 


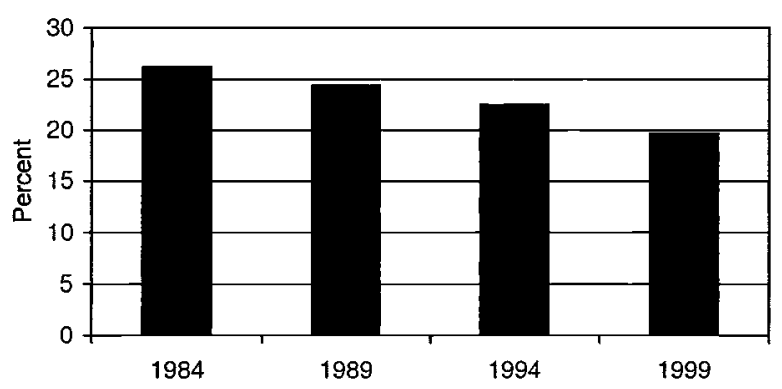

Fig. 5.1 Disability among the elderly

Source: Manton and Gu (2001).

intensive medical care receipt. These claims records figure prominently in the analysis reported here. Medicare covers hospital, physician, and laboratory services. Prescription drugs are not paid for by Medicare; hence, there is no record of them. Nor does the NLTCS ask about prescription medications. Thus, I cannot examine the role of pharmaceutical innovation.

Reliable hospital data are available from 1982 on. Physician data are generally not reliable until the early 1990s. To measure disability trends over the longest possible time period, I use data from 1989 and 1999, restricting myself to the hospital records. ${ }^{3}$ In practice, the most reliable information on hospital records is the major procedures that were performed. Surgical admissions are reimbursed at a higher rate than are medical admissions. Thus, hospitals take particular care in recording any surgical procedures that were performed. The procedures that I examine are all surgical.

Figure 5.1 shows basic information on trends in disability in 1984 and every five years thereafter (see Manton and $\mathrm{Gu}$ 2001). The data are age adjusted to the 1999 population; thus, the increasingly aged population does not mechanically lead to increased disability. In 1984, 26 percent of the elderly population was disabled. That declined steadily in the subsequent fifteen years. By 1999, less than 20 percent of the population was disabled. The overall decline in disability is 25 percent, or 1.8 percent per year. It is this major decline in disability that I seek to explain.

\subsection{Disabling Conditions and the Extent of Disability}

One way to begin the understanding of disability decline is to decompose disability changes into the incidence of different conditions and the extent

3. Analysis that I have done from the 1994 and 1999 surveys using physician data as well are generally similar. 
to which those conditions produce disability. Denote medical conditions by $j=1, \ldots, J$. Assuming that each person has only one condition, the probability that a person is disabled in any year is given by

$$
\operatorname{Pr}(\text { Disability })=\sum_{j} \operatorname{Pr}\left(C_{j}\right) \cdot \operatorname{Pr}\left(D \mid C_{j}\right),
$$

where $C_{j}$ is an indicator for whether a person has condition $j$ and $D$ indicates whether the person is disabled.

To operationalize this disaggregation, we need to define a set of conditions. The choices here are limited by the nature of the data. Whether the person is disabled can be determined from surveys conducted in 1989 and 1999. The only information on the incidence of disability conditions, however, comes from claims records. We thus need to find conditions that will be reliably coded in claims data.

In determining whether a person had a condition, we need to decide on a time period for measurement. The medical record data permit a measure of disease incidence over many years. Conditions that occurred many years in the past are unlikely to be a cause of current disability, however. To balance these concerns, I choose a time interval of two years before the survey date.

After some exploration, I settled on the thirty-three conditions listed in table 5.1. ${ }^{4}$ The conditions are divided by major diagnostic category. The major categories with the most entries include musculoskeletal disorders (for example, hip fractures and arthritis); respiratory disease (chronic obstructive pulmonary disease and similar diseases); circulatory disorders (stroke and heart disease); cancer (colorectal, lung, breast, and prostate); mental disorders (especially depression); nervous system disorders (dementia, Parkinson's); and endocrine disorders (especially diabetes). There are thirty-one specific diseases. The last row is the composite of other conditions. Some people who are disabled have no hospital admissions beforehand; these are included in the penultimate "no condition" row.

The last column of table 5.1 shows the share of people with that condition who were disabled in the individual survey. Admissions for dementia and other brain diseases have the highest disability rate. Three-quarters of people with such an admission are disabled. Other conditions with very high disability rates are hip and pelvic fractures (74 percent), paralysis and Parkinson's disease ( 73 percent), and acute renal failure (63 percent). At the bottom end, most cancers have only a 20 percent disability rate, and genitourinary diseases are similarly nondisabling. Somewhat surprisingly, 15 percent of people never admitted to a hospital in a two-year period are disabled at the end of that period.

These relative disability rates are important in considering equation (1). 


\begin{tabular}{|c|c|c|}
\hline Condition & ICD-9-CM codes & $\begin{array}{c}\text { Disability } \\
\text { probability }(\%)\end{array}$ \\
\hline \multicolumn{3}{|l|}{ Musculoskeletal } \\
\hline Arthritis and arthropathy & $274 .^{*}, 390 .^{*}, 710 .^{*}-716 .^{*}$ & 38 \\
\hline Back/Neck pain & $720 .^{*}-724 .^{*}, 839.0-839.5,846 .^{*}, 847 .^{*}$ & 31 \\
\hline Hip and pelvic fracture & $808 *{ }^{*}, 820 * *$ & 74 \\
\hline Musculoskeletal disorders & 717.*-739.*( \#29), 800.*-999.*( \#29,\#30) & 34 \\
\hline \multicolumn{3}{|l|}{ Digestive } \\
\hline Gastrointestinal disease & $530 .^{*}-579 . *, 789.0,787.0,787.7$ & 30 \\
\hline \multicolumn{3}{|l|}{ Respiratory } \\
\hline $\begin{array}{c}\text { Chronic obstructive pulmonary } \\
\text { diseases and related diseases }\end{array}$ & $466 .^{*}, 490 .^{*}-496 .^{*}, 518.12$ & 36 \\
\hline $\begin{array}{l}\text { Respiratory failure and } \\
\text { insufficiency }\end{array}$ & $518 .^{*}, 799.1$ & 46 \\
\hline Respiratory diseases & $\begin{array}{l}\text { 460.*-519.* ( \#22, \#23), 786.0, 786.1, 786.52, } \\
\quad 793.1\end{array}$ & 37 \\
\hline \multicolumn{3}{|l|}{ Circulatory } \\
\hline Stroke & $362.34,430 .^{*}, 431 .^{*}, 432.9,433 .^{*}-436 .^{*}$ & 50 \\
\hline Hypertension & $401 *^{*}-405 *(\sim \# 16), 437.0,437.9$ & 32 \\
\hline Ischemic heart disease & $410{ }^{*}-414 . *(\sim 414.11,414.19), 429.5-429.7$ & 30 \\
\hline Heart failure and arrhythmia & $425 .^{*}, 427.1,427.3-427.5,428 . *, 429.1,429.3$ & 46 \\
\hline Peripheral vascular disease & $\begin{array}{l}440 .^{*}, 442 .^{*}, 443 *^{*}(\sim 443.2), 444 .^{*}, 446 .^{*} \\
\quad 447 .^{*}(\sim 447.6), 451 .^{*}, 453.1\end{array}$ & 41 \\
\hline Circulatory diseases & $\begin{array}{l}391 . * 459 . *(\sim \# 13, \# 14, \# 16, \# 17, \# 18, \# 19, \\
\quad \# 20), 786.5, \mathrm{~V} 717 . *\end{array}$ & 32 \\
\hline \multicolumn{3}{|l|}{ Infectious disease } \\
\hline Infectious diseases & $001 .^{*}-139 .^{*}, 320 .^{*}-323 .^{*}, \mathrm{~V} 09 . *$ & 40 \\
\hline \multicolumn{3}{|l|}{ Cancer } \\
\hline Colorectal and lung cancer & $153 .^{*}, 154 .^{*}, 162 .^{*}$ & 30 \\
\hline Breast and prostate cancer & $174 .^{*}-175 .^{*}, 185 .^{*}$ & 20 \\
\hline Other cancers & $140{ }^{*}-239 . *(\sim \# 2, \# 3), 611.72, \mathrm{~V} 10$ & 23 \\
\hline \multicolumn{3}{|l|}{ Genitourinary diseases } \\
\hline Chronic renal failure & $\begin{array}{l}\text { 403.01, 403.11, 403.91, 404.02, 404.12, 404.92, } \\
\text { 585.*-586.*, V45.1, V56.* }\end{array}$ & 54 \\
\hline Acute renal failure and & $584 .^{*}, 587 .^{*}, 588 .^{*}$ & 63 \\
\hline Genitourinary diseases & 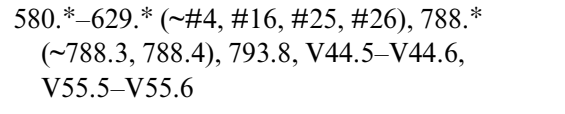 & 28 \\
\hline \multicolumn{3}{|l|}{ Mental disorders } \\
\hline Depression & $296 .^{*}(\sim 296.9), 298.0,300.4,311 .^{*}$ & 44 \\
\hline Other mental disorders & $290 .^{*}-319 .^{*}(\sim \# 10, \# 11), 797 .^{*}$ & 49 \\
\hline \multicolumn{3}{|l|}{ Nervous system and sensory } \\
\hline \multicolumn{3}{|l|}{ Dementia and organic brain } \\
\hline Paralysis, Parkinson's, etc. & $332 .^{*}, 340 .^{*}-344 .^{*}, 438 .^{*}$ & 73 \\
\hline Glaucoma and cataract & $365{ }^{*}-366 .^{*}, 743.2-743.3$ & 28 \\
\hline
\end{tabular}




\begin{tabular}{|c|c|c|}
\hline Condition & ICD-9-CM codes & $\begin{array}{c}\text { Disability } \\
\text { probability (\%) }\end{array}$ \\
\hline \multicolumn{3}{|l|}{ Blood } \\
\hline Anemia & $280{ }^{*}-285{ }^{*}$ & 43 \\
\hline Other blood diseases & $285 .^{*}-289 .^{*}$ & 37 \\
\hline \multicolumn{3}{|c|}{ Endocrine, nutritional, metabolic } \\
\hline Diabetes & $250 .^{*}, 251.3$ & 40 \\
\hline Thyroid disorders & $240 . *-259 . *(\sim \# 5)$ & 30 \\
\hline $\begin{array}{l}\text { Other metabolic and i } \\
\text { disorders }\end{array}$ & $270 .^{*}-273 .^{*}, 275 .^{*}-279 .^{*}$ & 28 \\
\hline \multicolumn{3}{|l|}{ Other } \\
\hline No condition & & 15 \\
\hline Composite category & All other codes & 29 \\
\hline
\end{tabular}

Equation (1) is only correct if each person has only one condition. In practice, some people have more than one condition. There is a generalization of equation (1) that allows for multiple conditions. ${ }^{5}$ The cross-correlations between conditions are generally fairly low, however, meaning that there are a lot of cross-conditions with few people in them.

To avoid dealing with many comorbidities with small numbers, I assign each person to only one condition - the one with the highest disability probability. For example, a person admitted with respiratory failure and insufficiency (46 percent disability rate) and diabetes (40 percent disability rate) is classified as having respiratory failure and insufficiency.

With this assignment system, table 5.2 shows how these conditions contribute to lower disability. The first two columns show the probability of having each condition and the disability associated with that condition in 1989; the next two columns report the same figures for 1999. The fifth and sixth columns show disability through each of these paths (the product of the two columns for that year), and the seventh column shows the change in disability from that path.

Overall, disability rates fell by 5.7 percentage points, as shown in the last row of the table. ${ }^{6}$ The biggest decline in disability comes from musculoskeletal disorders. Reduced disability through that channel accounts for onequarter of the total decline. Digestive and respiratory disorders together account for that amount as well. There is also a large decline in disability for people with no hospitalizations. This path accounts for 40 percent of the total reduction in disability.

5. Multiple conditions can conceptually be treated as conditions of their own. In practice, following this strategy does not change the conclusions.

6 . These numbers differ from those in figure 5.1 because of different years of age adjustment. 


\begin{tabular}{|c|c|c|c|c|c|c|c|c|}
\hline \multirow[b]{2}{*}{ Condition } & \multicolumn{2}{|c|}{1989} & \multicolumn{2}{|c|}{1999} & \multicolumn{4}{|c|}{ Disability probability } \\
\hline & $\operatorname{Pr}[\mathrm{C}]$ & $\operatorname{Pr}[\mathrm{D} \mid \mathrm{C}]$ & $\operatorname{Pr}[\mathrm{C}]$ & $\operatorname{Pr}[\mathrm{D} \mid \mathrm{C}]$ & 1989 & 1999 & Change & Total \\
\hline \multicolumn{9}{|l|}{ Musculoskeletal } \\
\hline 1 Arthritis and arthropathy & 2.6 & 37.4 & 3.6 & 25.0 & 1.0 & 0.9 & -0.1 & -1.3 \\
\hline 2 Back/Neck pain & 1.2 & 20.3 & 1.8 & 15.8 & 0.3 & 0.3 & 0.0 & \\
\hline 3 Hip and pelvic fracture & 1.8 & 77.1 & 1.4 & 67.8 & 1.4 & 0.9 & -0.5 & \\
\hline 4 Musculoskeletal disorders & 8.6 & 27.6 & 9.0 & 17.9 & 2.4 & 1.6 & -0.8 & \\
\hline \multicolumn{9}{|l|}{ Digestive } \\
\hline 5 Gastrointestinal disease & 4.9 & 21.0 & 3.1 & 12.2 & 1.0 & 0.4 & -0.6 & -0.6 \\
\hline \multicolumn{9}{|l|}{ Respiratory } \\
\hline $\begin{array}{l}6 \text { Chronic obstructive } \\
\text { pulmonary diseases and } \\
\text { related diseases }\end{array}$ & 1.9 & 31.6 & 2.1 & 17.2 & 0.6 & 0.4 & -0.2 & -0.6 \\
\hline $\begin{array}{l}7 \text { Respiratory failure and } \\
\text { insufficiency }\end{array}$ & 0.6 & 55.3 & 0.9 & 39.1 & 0.3 & 0.3 & 0.0 & \\
\hline 8 Respiratory diseases & 3.4 & 32.5 & 3.6 & 21.2 & 1.1 & 0.8 & -0.3 & \\
\hline \multicolumn{9}{|l|}{ Circulatory system } \\
\hline 9 Stroke & 3.8 & 51.2 & 4.7 & 39.1 & 1.9 & 1.8 & -0.1 & -0.3 \\
\hline 10 Hypertension & 1.5 & 22.0 & 2.5 & 16.0 & 0.3 & 0.4 & 0.1 & \\
\hline 11 Ischemic heart disease & 1.8 & 25.7 & 1.4 & 17.1 & 0.5 & 0.2 & -0.2 & \\
\hline $\begin{array}{l}12 \text { Heart failure and } \\
\text { arrhythmia }\end{array}$ & 3.6 & 43.3 & 5.3 & 37.0 & 1.6 & 2.0 & 0.4 & \\
\hline 13 Peripheral vascular disease & 1.3 & 35.7 & 1.5 & 24.2 & 0.5 & 0.4 & -0.1 & \\
\hline 14 Circulatory diseases & 3.3 & 22.5 & 2.8 & 12.3 & 0.8 & 0.3 & -0.4 & \\
\hline \multicolumn{9}{|l|}{ Infectious disease } \\
\hline 15 Infectious diseases & 1.4 & 39.8 & 1.4 & 25.9 & 0.5 & 0.4 & -0.2 & -0.2 \\
\hline \multicolumn{9}{|l|}{ Cancer } \\
\hline $\begin{array}{l}16 \text { Colorectal and lung } \\
\text { cancer }\end{array}$ & 0.3 & 23.4 & 0.1 & 31.0 & 0.1 & 0.0 & 0.0 & -0.1 \\
\hline 17 Breast and prostate cancer & 0.2 & 13.5 & 0.2 & 14.9 & 0.0 & 0.0 & 0.0 & \\
\hline 18 Other cancers & 1.1 & 12.8 & 0.6 & 7.5 & 0.1 & 0.0 & -0.1 & \\
\hline \multicolumn{9}{|l|}{ Genitourinary diseases } \\
\hline 19 Chronic renal failure & 0.3 & 59.0 & 0.5 & 52.5 & 0.2 & 0.3 & 0.1 & -0.1 \\
\hline \multicolumn{9}{|l|}{20 Acute renal failure and } \\
\hline 21 Genitourinary diseases & 2.2 & 17.2 & 1.1 & 14.6 & 0.4 & 0.2 & -0.2 & \\
\hline \multicolumn{9}{|l|}{ Mental disorders } \\
\hline 22 Depression & 0.3 & 23.7 & 0.5 & 33.0 & 0.1 & 0.2 & 0.1 & 0.0 \\
\hline 23 Other mental disorders & 1.4 & 41.5 & 1.3 & 36.9 & 0.6 & 0.5 & -0.1 & \\
\hline \multicolumn{9}{|l|}{ Nervous system and sense organs } \\
\hline $\begin{array}{l}24 \text { Dementia and organic } \\
\text { brain diseases }\end{array}$ & 1.1 & 82.2 & 1.5 & 77.5 & 0.9 & 1.2 & 0.3 & 0.1 \\
\hline 25 Paralysis, Parkinson's, etc. & 1.0 & 70.0 & 1.1 & 67.0 & 0.7 & 0.7 & 0.0 & \\
\hline 26 Glaucoma and cataract & 1.4 & 25.0 & 0.7 & 13.8 & 0.3 & 0.1 & -0.2 & \\
\hline
\end{tabular}


(continued)

\begin{tabular}{|c|c|c|c|c|c|c|c|c|}
\hline \multirow[b]{2}{*}{ Condition } & \multicolumn{2}{|c|}{1989} & \multicolumn{2}{|c|}{1999} & \multicolumn{4}{|c|}{ Disability probability } \\
\hline & $\operatorname{Pr}[\mathrm{C}]$ & $\operatorname{Pr}[\mathrm{D} \mid \mathrm{C}]$ & $\operatorname{Pr}[\mathrm{C}]$ & $\operatorname{Pr}[\mathrm{D} \mid \mathrm{C}]$ & 1989 & 1999 & Change & Total \\
\hline \multicolumn{9}{|l|}{ Blood } \\
\hline 27 Anemia & 1.4 & 37.4 & 2.1 & 30.7 & 0.5 & 0.6 & 0.1 & 0.1 \\
\hline 28 Other blood diseases & 0.4 & 11.5 & 0.4 & 14.3 & 0.0 & 0.1 & 0.0 & \\
\hline \multicolumn{9}{|c|}{ Endocrine, nutritional, metabolic } \\
\hline 29 Diabetes & 2.2 & 31.3 & 3.9 & 24.9 & 0.7 & 1.0 & 0.3 & 0.2 \\
\hline Thyroid disorders & 0.3 & 14.6 & 0.5 & 4.8 & 0.0 & 0.0 & 0.0 & \\
\hline $\begin{array}{l}31 \text { Other metabolic and } \\
\text { immunity disorders }\end{array}$ & 0.4 & 30.8 & 0.3 & 8.2 & 0.1 & 0.0 & -0.1 & \\
\hline \multicolumn{9}{|l|}{ Other } \\
\hline 32 No condition & 37.1 & 17.2 & 31.7 & 12.8 & 6.4 & 4.1 & -2.3 & -2.8 \\
\hline 33 Composite category & 7.3 & 22.0 & 8.3 & 13.2 & 1.6 & 1.1 & -0.5 & \\
\hline Total & & 26.9 & & 21.2 & & & -5.7 & \\
\hline
\end{tabular}

Notes: These are weighted (using CDS screener cross-sectional weights) observed rates in 1989 and 1999. Weights are age and sex standardized to 1999.

Table 5.2 suggests a mixed conclusion about the potential importance of intensive interventions in explaining the decline in disability. Musculoskeletal disorders are certainly responsive to medical intervention; hip replacements and back or neck procedures are among the most rapidly expanding medical procedures. On the other hand, there is little surgical therapy for infectious disease and respiratory disease, each of which have had reductions in disability. And clearly, no surgical therapy was performed on people without a hospital record. Increased use of intensive therapies can thus explain some, but certainly not all, of the reduction in disability.

\subsubsection{Incidence of Conditions and Disability Rate}

More information on the nature of reduced disability comes from decomposing disability declines into changes in the probability of having a disease and the extent to which diseases lead to disability. Following equation (1), we can approximate ${ }^{7}$ the change in disability between two time periods as

$$
\text { (2) } \Delta \operatorname{Pr}(\text { Disability })=\sum_{j} \Delta \operatorname{Pr}\left(C_{j}\right) \cdot \operatorname{Pr}\left(D \mid C_{j}\right)+\sum_{j} \operatorname{Pr}\left(C_{j}\right) \cdot \Delta \operatorname{Pr}\left(D \mid C_{j}\right) \text {. }
$$

The first term on the right-hand side is the effect of changes in event probabilities on disability; the second is the effect of changes in the conditional disability rate. Performing this decomposition will tell us whether

7. The equation is approximate because there is an omitted covariance term between changes in incidence and conditional disability rates. 
disability is falling because fewer people are at risk for disability or because the same events are less disabling over time. Intensive medical care will be more likely to reduce disability among people with a disease than to prevent the disease in the first place.

Table 5.3 shows the decomposition. In total, more people have conditions in 1999 than did in 1989. As the penultimate row shows, 5.4 percent fewer people had no condition in 1999 than did in 1989. As a result of this increase in the probability of having disabling conditions, changes in the event probability rate alone would suggest an increase in disability over time. The amount, shown in the last row of the table, is 1.8 percent.

The overwhelming reason why disability has declined is because the conditions that people have are less disabling than they used to be. This finding is true for the vast bulk of conditions. For the typical condition, the disability rate for people who have the condition was about 10 percent lower in 1999 than it was a decade earlier.

The findings that more people have each condition and that fewer people with each condition are disabled suggests a possible selection story - more people survive severe episodes now than in the past and thus report hospitalizations for them. That would not be a particular problem for the analysis; we want to capture increasing disability resulting from more "marginal survivors."

Two other possibilities are more problematic, however. One possibility is that diagnosis of marginal cases has increased, and the new people with each condition are not as seriously affected as those who were diagnosed previously. This would lead to a mechanical finding that the incidence of disabling conditions was rising but that disability for people with those conditions was falling. Since the conditions chosen are generally severe and relatively clear to diagnose, however, this is somewhat less likely. A hip fracture is not a very ambiguous diagnosis, for example.

Alternatively, it may be that people have these diagnoses because they are obtaining particular therapies that were not previously provided. For example, a person with severe arthritis who now receives a hip replacement will be admitted to a hospital for the operation and receive an arthritis drug, where previously there was no admission for that condition. In these data, we have no way to test for this. It is thus necessary to interpret the decomposition with some caution.

\subsection{Intensive Medical Care and Disability}

The question I address is how much of the reduction in disability can be explained by increased use of intensive procedures. To assemble a list of important interventions, I looked at the procedures that are common for these diseases. Table 5.4 shows the resulting list, and table 5.5 shows a concordance between diseases and procedures. Relevant procedures differ 


\begin{tabular}{|c|c|c|c|c|c|c|}
\hline \multirow[b]{3}{*}{ Condition } & \multicolumn{6}{|c|}{ Effect of change in: } \\
\hline & \multicolumn{3}{|c|}{ Probability of condition } & \multicolumn{3}{|c|}{ Conditional disability rate } \\
\hline & $\mathrm{d} \operatorname{Pr}[\mathrm{C}]$ & $\operatorname{Pr}[\mathrm{D} \mid \mathrm{C}]$ & Total & $d(\operatorname{Pr}[D \mid C])$ & $\operatorname{Pr}[\mathrm{C}]$ & Total \\
\hline \multicolumn{7}{|l|}{ Musculoskeletal } \\
\hline 1 Arthritis and arthropathy & 1.0 & 37.4 & 0.4 & -12.4 & 2.6 & -0.3 \\
\hline 2 Back/Neck pain & 0.5 & 20.3 & 0.1 & -4.5 & 1.2 & -0.1 \\
\hline 3 Hip and pelvic fracture & -0.4 & 77.1 & -0.3 & -9.3 & 1.8 & -0.2 \\
\hline 4 Musculoskeletal disorders & 0.4 & 27.6 & 0.1 & -9.8 & 8.6 & -0.8 \\
\hline \multicolumn{7}{|l|}{ Digestive } \\
\hline 5 Gastrointestinal disease & -1.8 & 21.0 & -0.4 & -8.8 & 4.9 & -0.4 \\
\hline \multicolumn{7}{|l|}{ Respiratory } \\
\hline $\begin{array}{l}6 \text { Chronic obstructive pulmonary } \\
\text { diseases and related diseases }\end{array}$ & 0.2 & 31.6 & 0.1 & -14.4 & 1.9 & -0.3 \\
\hline 7 Respiratory failure and insufficiency & 0.3 & 55.3 & 0.1 & -16.3 & 0.6 & -0.1 \\
\hline 8 Respiratory diseases & 0.2 & 32.5 & 0.1 & -11.3 & 3.4 & -0.4 \\
\hline \multicolumn{7}{|l|}{ Circulatory system } \\
\hline 9 Stroke & 0.9 & 51.2 & 0.5 & -12.1 & 3.8 & -0.5 \\
\hline 10 Hypertension & 1.0 & 22.0 & 0.2 & -6.0 & 1.5 & -0.1 \\
\hline 11 Ischemic heart disease & -0.4 & 25.7 & -0.1 & -8.6 & 1.8 & -0.2 \\
\hline 12 Heart failure and arrhythmia & 1.7 & 43.3 & 0.7 & -6.3 & 3.6 & -0.2 \\
\hline 13 Peripheral vascular disease & 0.2 & 35.7 & 0.1 & -11.5 & 1.3 & -0.1 \\
\hline 14 Circulatory diseases & -0.6 & 22.5 & -0.1 & -10.2 & 3.3 & -0.3 \\
\hline \multicolumn{7}{|l|}{ Infectious disease } \\
\hline 15 Infectious diseases & 0.0 & 39.8 & 0.0 & -13.9 & 1.4 & -0.2 \\
\hline \multicolumn{7}{|l|}{ Cancer } \\
\hline 16 Colorectal and lung cancer & -0.2 & 23.4 & 0.0 & 7.5 & 0.3 & 0.0 \\
\hline 17 Breast and prostate cancer & 0.0 & 13.5 & 0.0 & 1.5 & 0.2 & 0.0 \\
\hline 18 Other cancers & -0.5 & 12.8 & -0.1 & -5.2 & 1.1 & -0.1 \\
\hline \multicolumn{7}{|l|}{ Genitourinary diseases } \\
\hline 19 Chronic renal failure & 0.2 & 59.0 & 0.1 & -6.5 & 0.3 & 0.0 \\
\hline 20 Acute renal failure and insufficiency & 0.1 & 74.5 & 0.1 & -19.7 & 0.1 & 0.0 \\
\hline 21 Genitourinary diseases & -1.1 & 17.2 & -0.2 & -2.7 & 2.2 & -0.1 \\
\hline \multicolumn{7}{|l|}{ Mental disorders } \\
\hline 22 Depression & 0.2 & 23.7 & 0.0 & 9.3 & 0.3 & 0.0 \\
\hline 23 Other mental disorders & -0.1 & 41.5 & 0.0 & -4.6 & 1.4 & -0.1 \\
\hline \multicolumn{7}{|l|}{ Nervous system and sense organs } \\
\hline 24 Dementia and organic brain diseases & 0.5 & 82.2 & 0.4 & -4.7 & 1.1 & 0.0 \\
\hline 25 Paralysis, Parkinson's, etc. & 0.1 & 70.0 & 0.1 & -2.9 & 1.0 & 0.0 \\
\hline 26 Glaucoma and cataract & -0.7 & 25.0 & -0.2 & -11.3 & 1.4 & -0.2 \\
\hline \multicolumn{7}{|l|}{ Blood } \\
\hline 27 Anemia & 0.7 & 37.4 & 0.3 & -6.7 & 1.4 & -0.1 \\
\hline $\begin{array}{l}28 \text { Other blood diseases } \\
\text { (continued) }\end{array}$ & 0.0 & 11.5 & 0.0 & 2.9 & 0.4 & 0.0 \\
\hline
\end{tabular}


Table 5.3 (continued)

\begin{tabular}{|c|c|c|c|c|c|c|c|}
\hline \multirow{3}{*}{\multicolumn{2}{|c|}{ Condition }} & \multicolumn{6}{|c|}{ Effect of change in: } \\
\hline & & \multicolumn{3}{|c|}{ Probability of condition } & \multicolumn{3}{|c|}{ Conditional disability rate } \\
\hline & & $\mathrm{dPr}[\mathrm{C}]$ & $\operatorname{Pr}[\mathrm{D} \mid \mathrm{C}]$ & Total & $\mathrm{d}(\operatorname{Pr}[\mathrm{D} \mid \mathrm{C}])$ & $\operatorname{Pr}[\mathrm{C}]$ & Total \\
\hline \multicolumn{8}{|c|}{ Endocrine, nutritional, metabolic } \\
\hline 29 & Diabetes & 1.7 & 31.3 & 0.5 & -6.4 & 2.2 & -0.1 \\
\hline 30 & Thyroid disorders & 0.1 & 14.6 & 0.0 & -9.7 & 0.3 & 0.0 \\
\hline 31 & Other metabolic and immunity disorders & $\mathrm{s}-0.1$ & 30.8 & 0.0 & -22.6 & 0.4 & -0.1 \\
\hline \multicolumn{8}{|c|}{ Other } \\
\hline & No condition & -5.4 & 17.2 & -0.9 & -4.4 & 37.1 & -1.6 \\
\hline & Composite category & 1.0 & 22.0 & 0.2 & -8.8 & 7.3 & -0.6 \\
\hline \multicolumn{4}{|c|}{ Total } & 1.8 & & & -7.2 \\
\hline
\end{tabular}

Note: See table 5.2 notes.

Table 5.4

List of common procedures

\begin{tabular}{|c|c|c|}
\hline \multicolumn{2}{|c|}{ No./Procedure } & \multirow{2}{*}{$\frac{\text { ICD-9-CM codes }}{03 *^{*}(\sim 03.3)}$} \\
\hline 3 & Ops on spinal cord and spinal canal structures & \\
\hline 13 & Ops on lens & $13 .^{*}$ \\
\hline 14 & Ops on retina, choroid, vitreous, and posterior chamber & $14{ }^{*}(\sim 14.1)$ \\
\hline 34 & Ops on chest wall, pleura, mediastinum, and diaphragm & $34 . *(\sim 34.2)$ \\
\hline 35 & Ops on valves and septa of heart & $35 .^{*}$ \\
\hline 36 & Ops on vessels of heart & $36 .^{*}$ \\
\hline 37 & Other ops on heart and pericardium & $37 *(\sim 37.2)$ \\
\hline 38 & Incision, excision, and occlusion of vessels & $38 *(\sim 38.2)$ \\
\hline 39 & Other ops on vessels & $39 . *$ \\
\hline 45 & Incision, excision, and anastomosis of intestine & $45.0(\sim 45.1,45.2)$ \\
\hline 51 & Ops on gallbladder and biliary tract & $51 *(\sim 51.1)$ \\
\hline 53 & Repair of hernia & $53 .^{*}$ \\
\hline 54 & Other ops on abdominal region & $54 *(\sim 52.2)$ \\
\hline 57 & Ops on urinary bladder & $57 *(\sim 57.3)$ \\
\hline 60 & Ops on prostate and seminal vesicles & $60 *(\sim 60.1)$ \\
\hline 79 & Reduction of fracture and dislocation & $79 . *$ \\
\hline 80 & Incision and excision of joint structures & $80 .^{*}$ \\
\hline 81 & Repair and plastic ops on joint structures & $81 * *$ \\
\hline 84 & Other procedures on musculoskeletal system & $84 .^{*}$ \\
\hline 85 & Ops on the breast & $85 .^{*}$ \\
\hline 99 & Conversion of cardiac rhythm & 99.6 \\
\hline
\end{tabular}

greatly across diseases. People with musculoskeletal diagnoses receive joint replacement and other surgeries, for example, and people with cardiovascular disease receive various heart procedures. For some conditions-respiratory problems, mental illness, and nervous system disorders - no surgical therapy is common. 


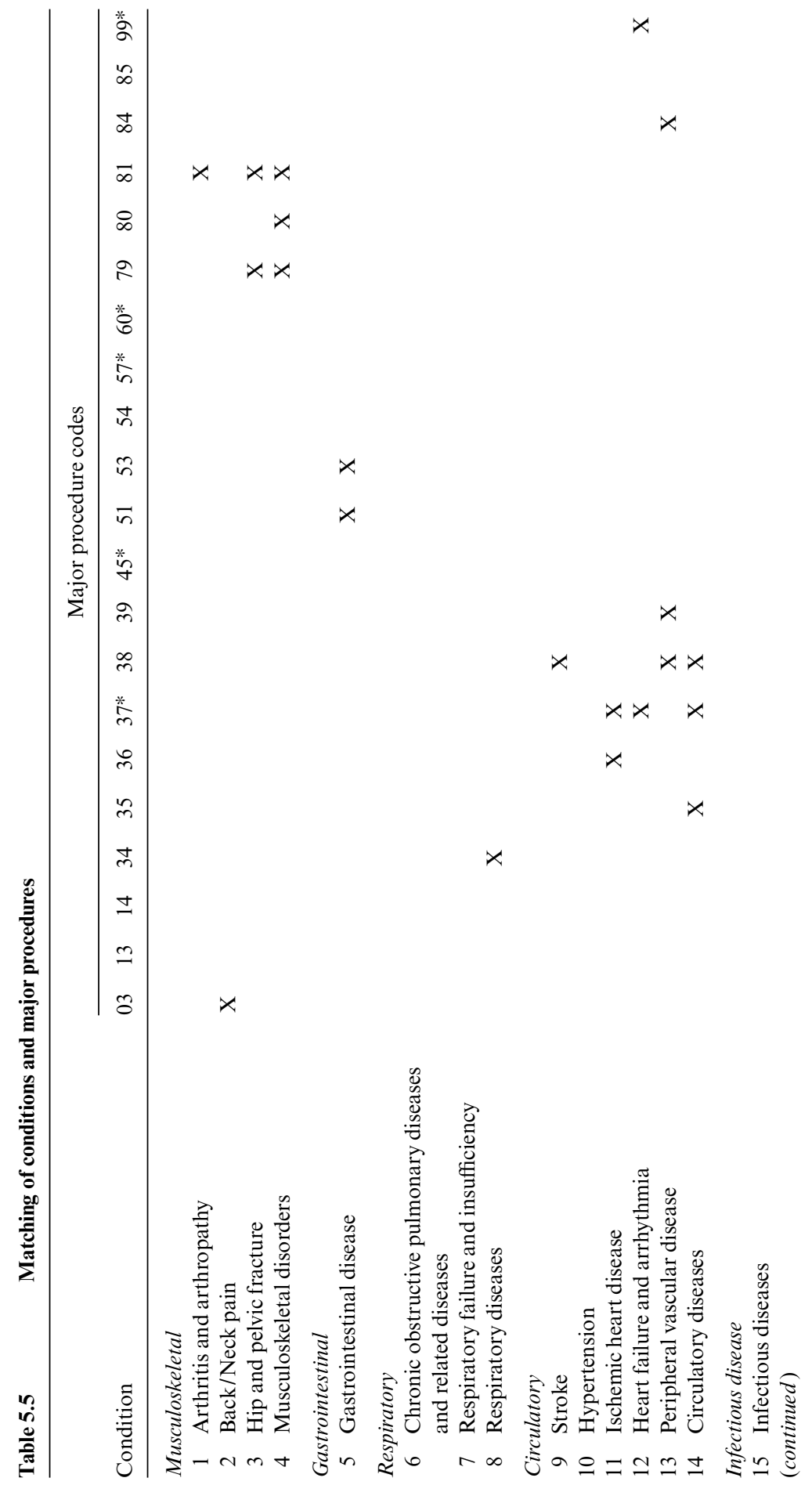




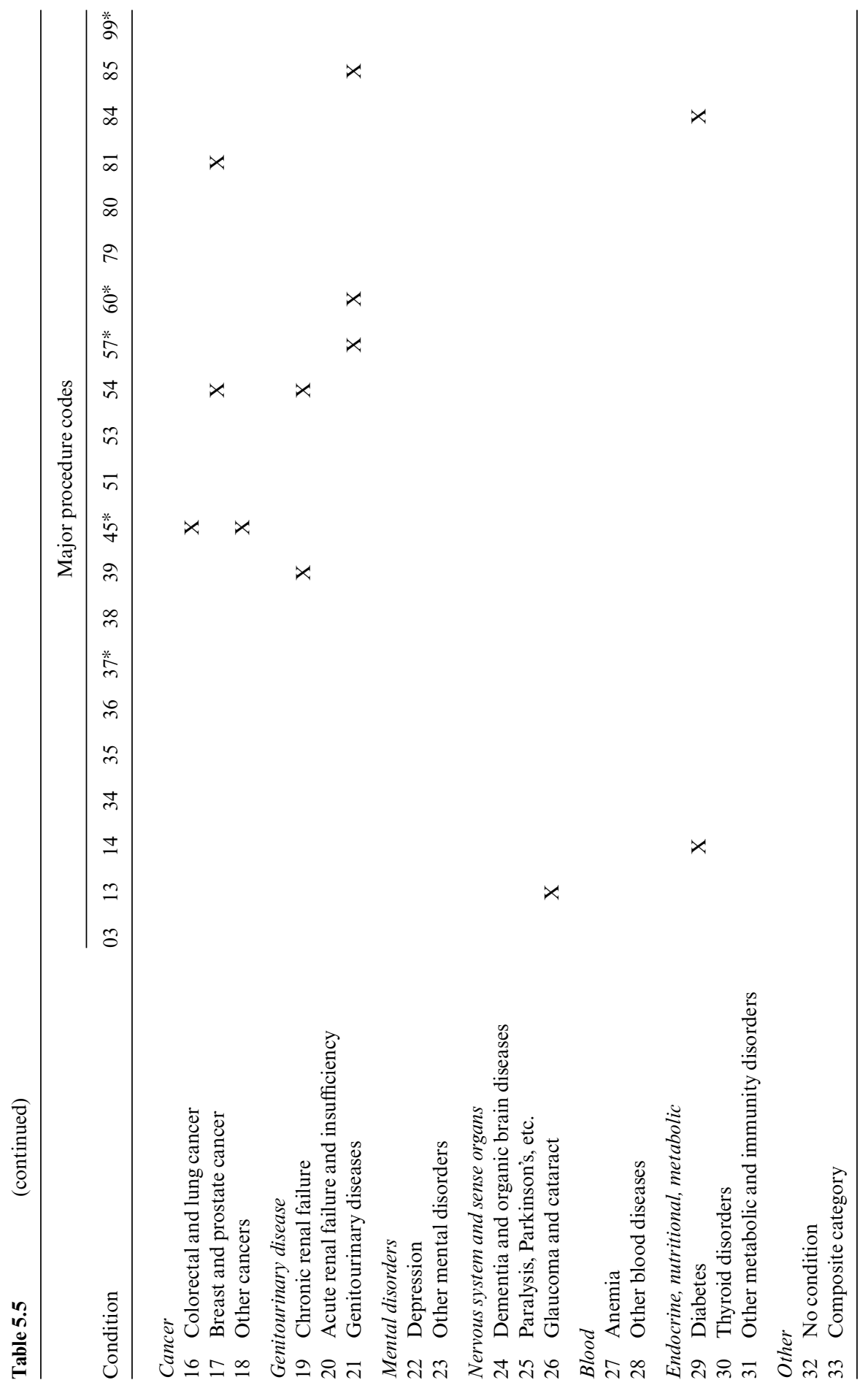


Table 5.6 shows the share of people with each condition that received any of the indicated surgeries. There is a large increase in use of most procedures over time. Surgical increases are very common for patients with musculoskeletal disorders; the percent of patients receiving surgery rose by as much as 20 percent for many of these conditions. Surgery also increased substantially for patients with circulatory disorders (especially heart disease) and difficulty seeing. Surgical increases were much smaller, or declined, for patients with respiratory problems and cancer. The lower rate of use of surgery for cancer patients is somewhat troubling, since almost all such patients will receive some surgery. Most likely, the admissions for cancer here are palliative care patients, or patients who previously had surgery and are now admitted for other therapies. These types of problems point out the limitations of using claims data, but there is no alternative in this case.

Estimating the impact of medical therapies on disability is difficult. Consider a cross-sectional regression relating disability to an indicator for whether a person received an intensive procedure and a variety of other factors $(\mathbf{X})$ :

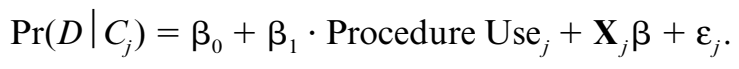

The difficulty with estimating this equation is the nonrandom decision about who receives which treatment. If the most severely ill patients receive surgical care and are also likely to wind up disabled, the regression will show that surgical procedure use is positively associated with disability, when that is not the case. Some measures of sickness can be controlled for in the $\mathbf{X}$ vector, but not all. Without an instrument for who receives different procedures that is independent of illness severity and general health status, there is no easy solution to this problem.

To make progress, I use time series rather than cross-section variation. The idea is the following: suppose that the underlying severity of disease for each condition is the same over time. Then, conditions where procedure use has expanded most should have the largest decline in disability. Formally, this can be expressed as

$$
\Delta \operatorname{Pr}\left(D \mid C_{j}\right)=\beta_{0}+\beta_{1} \cdot \Delta \text { Procedure } \text { Use }_{j}+\varepsilon_{j},
$$

where $\Delta$ Procedure $\mathrm{Use}_{j}$ is the average change in procedure use for people with each condition.

The identifying assumption here is that patient severity is the same over time (hence, equation [4] can be estimated without $\mathbf{X}$ variables). The increase in diagnosis of these conditions makes this somewhat problematic. More patients diagnosed may raise or lower average severity of the group with each condition. Future work could usefully address this by looking at changes in comorbidities or other factors that illustrate disease severity.

Another concern is that other factors might influence disability. Imagine 


\begin{tabular}{|c|c|c|c|c|c|}
\hline \multirow[b]{2}{*}{ Condition } & \multicolumn{2}{|l|}{1989} & \multicolumn{2}{|l|}{1999} & \multirow[b]{2}{*}{ Change $(\%)$} \\
\hline & $\%$ of surgery & $N$ & $\%$ of surgery & $N$ & \\
\hline \multicolumn{6}{|l|}{ Musculoskeletal } \\
\hline 1 Arthritis and arthropathy & 12.1 & 407 & 29.4 & 588 & 17.3 \\
\hline 2 Back/Neck pain & 6.2 & 177 & 16.1 & 279 & 9.9 \\
\hline 3 Hip and pelvic fracture & 52.8 & 291 & 73.7 & 264 & 20.9 \\
\hline 4 Musculoskeletal disorders & 6.9 & 1,292 & 8.0 & 1,440 & 1.1 \\
\hline \multicolumn{6}{|l|}{ Digestive } \\
\hline 5 Gastrointestinal disease & 16.9 & 716 & 18.0 & 485 & 1.1 \\
\hline \multicolumn{6}{|l|}{ Respiratory } \\
\hline $\begin{array}{l}6 \text { Chronic obstructive pulmonary diseases } \\
\text { and related diseases }\end{array}$ & - & & - & & \\
\hline 7 Respiratory failure and insufficiency & - & & - & & \\
\hline 8 Respiratory diseases & 3.9 & 524 & 1.2 & 579 & -2.7 \\
\hline \multicolumn{6}{|l|}{ Circulatory } \\
\hline 9 Stroke & 9.5 & 579 & 12.0 & 805 & 2.5 \\
\hline 10 Hypertension & - & & - & & \\
\hline 11 Ischemic heart disease & 13.4 & 269 & 27.3 & 205 & 13.9 \\
\hline 12 Heart failure and arrhythmia & 4.5 & 549 & 10.2 & 954 & 5.7 \\
\hline 13 Peripheral vascular disease & 23.7 & 198 & 27.5 & 232 & 3.8 \\
\hline 14 Circulatory diseases & 7.1 & 495 & 7.5 & 418 & 0.4 \\
\hline \multicolumn{6}{|l|}{ Infectious disease } \\
\hline 15 Infectious diseases & - & & - & & \\
\hline \multicolumn{6}{|l|}{ Cancer } \\
\hline 16 Colorectal and lung cancer & 40.4 & 40 & 18.1 & 19 & -22.3 \\
\hline 17 Breast and prostate cancer & 35.7 & 28 & 19.1 & 37 & -16.6 \\
\hline 18 Other cancers & 5.7 & 166 & 22.2 & 98 & 16.5 \\
\hline \multicolumn{6}{|l|}{ Genitourinary diseases } \\
\hline 19 Chronic renal failure & 48.3 & 40 & 43.1 & 80 & -5.2 \\
\hline 20 Acute renal failure and insufficiency & - & & - & & \\
\hline 21 Genitourinary diseases & 22.3 & 315 & 13.4 & 172 & -8.9 \\
\hline \multicolumn{6}{|l|}{ Mental disorders } \\
\hline 22 Depression & - & & - & & \\
\hline 23 Other mental disorders & - & & - & & \\
\hline \multicolumn{6}{|l|}{ Nervous system and sensory } \\
\hline 24 Dementia and organic brain diseases & - & & - & & \\
\hline 25 Paralysis, Parkinson’s, etc. & - & & - & & \\
\hline 26 Glaucoma and cataract & 55.2 & 207 & 73.3 & 122 & 18.1 \\
\hline \multicolumn{6}{|l|}{ Blood } \\
\hline 27 Anemia & - & & - & & \\
\hline 28 Other blood diseases & - & & - & & \\
\hline \multicolumn{6}{|l|}{ Endocrine, nutritional, metabolic } \\
\hline 29 Diabetes & 5.1 & 328 & 1.4 & 595 & -3.7 \\
\hline 30 Thyroid disorders & - & & - & & \\
\hline 31 Other metabolic and immunity disorders & - & & - & & \\
\hline \multicolumn{6}{|l|}{ Other } \\
\hline 32 No condition & - & & - & & \\
\hline 33 Composite category & - & & - & & \\
\hline
\end{tabular}

Notes: Surgeries are listed in table 5.5. Dashes indicate that no surgical procedures were identified. 
that a new pharmaceutical is developed that substitutes for surgery in some cases. Surgery rates will fall, and concomitantly disability will decline. This will bias the findings against showing an impact of medical technology on health, although the opposite bias is possible as well. One task for the future will be to consider which of these conditions have had important nonsurgical advances in treatments - pharmaceutical, environmental, or behavioral. For now, however, I do not address this.

Figure 5.2 shows the graphical relation between changes in intensive procedure use and disability rates for people who have been diagnosed with these conditions (the conditional disability rate). There is a clear negative relation between the two. The coefficient $\beta_{1}$ in the regression above is estimated to be -.27 (.13). The $R^{2}$ from the regression is not high (.13), but that is not particularly surprising: there are many factors other than surgical procedures that influence disability.

A comparison of the different disease categories indicates what is being picked up in the analysis. Intensive procedure use rose particularly rapidly for people with musculoskeletal problems. The increase in use was as high as 20 percent for some conditions. Those conditions also had very large declines in disability, placing them in the bottom right quadrant of the figure. Surgery rates for cancer fell or were relatively constant, however, and disability rates for cancer rose. Cancer diagnoses make up many of the conditions toward the top left of the figure.

Overall, increased use of surgical procedures does not explain a large part of the total reduction in disability. The constant term in the regression - the predicted change in disability with no change in surgery ratesis about 7 percent. That is near the overall decline in conditional disability rates shown in table 5.3. Further, the very strong declines in disability for conditions where surgery is not an option show the importance of other factors. Surgery seems to be important for some specific conditions, such

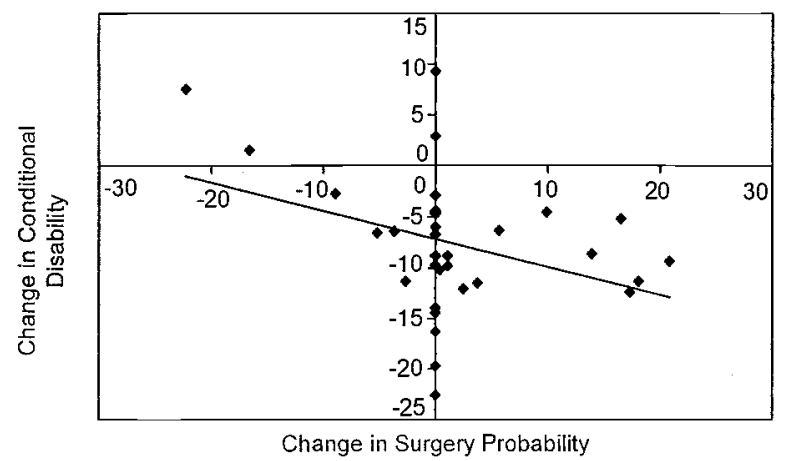

Fig. 5.2 Change in probability of surgery and conditional disability

Source: Author's calculations based on data from the National Long-Term Care Survey. 
as musculoskeletal disease and circulatory disorders, but is not a major part of the decline for the vast bulk of patients.

\subsection{Conclusions}

This paper is a preliminary look at the factors leading to reduced disability among the elderly in the past two decades. Although the analysis is still at the beginning stages, there are several important results. The data show that lower disability is almost exclusively a result of reduced disability for people who experience serious diseases rather than a result of fewer people having serious diseases. The share of people who report having a serious condition is actually rising over this time period, and the overall disability rate among the elderly would have increased were the health of the disabled not improving. The substantial reduction in disability conditional on disease incidence strongly suggests the possibility that medical care is a factor in improved health.

Examining one important part of medical care - the use of intensive surgical therapy-yields mixed results. Rates of surgery increased for many disease categories. For conditions such as musculoskeletal problems and circulatory disorders, higher rates of surgery are plausibly related to reduced disability. But that is not true for all conditions. Many conditions are not treated by surgical intervention, and yet disability for those conditions fell as well. It is clear that other factors are also important in explaining the better health of the elderly. Determining what those other factors are is the subject of ongoing research. This paper presents a framework to examine such effects, and data that can shed light on the answers.

\section{References}

Cutler, David M. 2001. Declining disability among the elderly. Health Affairs 20 (6): $11-27$.

Freedman, Vicki A., and Linda G. Martin. 2002. The role of education in explaining and forecasting trends in functional limitations among older Americans. Demography 36 (4): 461-73.

Freedman, Vicki A., Linda G. Martin, and Robert F. Schoeni. 2002. Recent trends in disability and functioning among older adults in the United States: A systematic review. Journal of the American Medical Association 288 (24): 3137-46.

Institute of Medicine. 1997. Enabling America: Assessing the role of rehabilitation science and engineering. Washington, DC: National Academy Press.

Manton, Kenneth G., Larry S. Corder, and Eric Stallard. 1993. Changes in the use of personal assistance and special equipment from 1982 to 1989: Results from the 1982 and 1989 NLTCS. Gerontologist 33 (2): 768-77.

Manton, Kenneth G., and Xiliang Gu. 2001. Changes in the prevalence of chronic 
disability in the United States black and nonblack population above age 65 from 1982 to 1999. Proceedings of the National Academy of Sciences 98 (11): 6354-59.

McClellan, Mark, and Lijing Yan. 2000. Understanding disability trends in the US elderly population: The role of disease management and disease prevention. Stanford University, Department of Economics. Mimeograph.

Pardes, Herb, Kenneth G. Manton, Eric S. Lander, H. Dennis Tolley, Arthur D. U1lian, and Hans Palmer. 1999. Effects of medical research on health care and the economy. Science 283:36-37.

Pope, Andrew M., and Alvin Tarlov, eds. 1991. Disability in America: Toward a national agenda for prevention. Washington, DC: National Academy Press.

Verbrugge, Lois M., and Alan M. Jette. 1994. The disablement process. Social Science and Medicine 38 (1): 1-14.

\section{Comment Alan M. Garber}

The Medicare Coverage Advisory Committee, appointed by the Health Care Financing Administration (now HCFA) to help the Medicare program make decisions about the coverage of specific medical procedures and products, met in March of 2003 to consider a promising new technology for the treatment of congestive heart failure. The technology, known as a left ventricular assist device (LVAD), was originally approved as a "bridge" to heart transplantation for patients with far advanced heart failure. Because the number of Americans with end-stage congestive heart failure greatly exceeds the number who could receive heart transplants, interest grew in the use of these devices as "destination therapy"- that is, as the primary treatment for people who could not receive transplants.

The LVAD is a portable device that acts as an external pump to assist in moving blood throughout the body, taking over part of the job of the irreversibly weakened heart of patients with very severe congestive heart failure. In a major clinical trial (REMATCH; Rose et al. 2001), patients who were near death from congestive heart failure were randomly assigned to treatment with LVAD placement or standard medical therapy. After twelve months of treatment, nearly 80 percent of the medically treated patients had died, while about half of the LVAD treated patients had died. Complementing the greater survival rate of the LVAD patients was evidence of improved quality of life. For example, the LVAD-treated group was less likely to be depressed at the end of one year, and the severity of congestive heart failure (New York Hospital Association score) was much lower in the LVAD group. The trial established that the LVAD improved survival and

Alan M. Garber is a staff physician with the Veterans Affairs Palo Alto Health Care System, the Henry J. Kaiser, Jr., Professor and professor of medicine at Stanford University, and a research associate and director of the Health Care Program at the National Bureau of Economic Research. 
at least some dimensions of quality of life among patients with severe congestive heart failure. Thus, this technological innovation improved survival and, apparently, functional status. Because the prevalence of congestive heart failure rises with age and the syndrome is very common among Medicare beneficiaries, the LVAD has the potential to contribute to future decreases in disability among the elderly.

Recent findings that the prevalence of disability has been declining among older Americans have encouraged optimism about the health of future cohorts of elderly Americans. The potential ramifications of declining old age disability include longer working lives, diminishing needs for medical and long-term care, and general improvements in the quality of life. Particularly for aging baby boomers, these implications are momentous, since they determine how this outsized cohort will spend an increasingly large fraction of their lives. A better understanding of the causes of the disability decline might enable us to intervene to promote further declines in disability, while helping us to know which aspects of progress would be inadvertently threatened - or encouraged - by changes in health care financing and utilization. David Cutler's paper takes an important step toward addressing these issues by outlining an approach that relates changes in disability to changes in the use of major medical procedures. His approach, if it is successful, will elucidate the roles of devices like LVADs and other, less dramatic, procedures that may have contributed to the disability decline.

\section{The Disability Decline and Its Causes}

Findings of declining disability rates among the elderly shifted the balance of a long-standing debate about disability trends. Many prominent researchers hypothesized that medical advances were succeeding in keeping people alive whose health conditions would have led to an earlier death in years past (Verbrugge 1984). Though they could now survive longer with their chronic conditions, they suffered greater impairments than previous cohorts of survivors. This view of changes in health is based on the idea that medical progress affects survival more than functional status. The automated implantable defibrillator, which prevents sudden cardiac death by administering a shock to the heart when it goes into a deadly arrhythmia, is a recently introduced technology that reduces death rates but does little or nothing to alter the conditions that predispose patients to suffer sudden cardiac death, such as coronary artery disease and congestive heart failure.

My Stanford colleague James Fries argued more than two decades ago that trends pointed toward declining, not rising, old age disability (Fries 1980). Reductions in the incidence and severity of chronic diseases, he claimed, would lead to reductions in the disability caused by those diseases. Treatment of elevated blood pressure, for example, prevents death from stroke by preventing the strokes themselves. Prevention of this com- 
mon complication of hypertension could result in declining age-adjusted functional limitations attributable to stroke survivors.

Trends in disability seemed to vary with the specific disease or health condition, and, until Kenneth Manton published his findings from the National Long-Term Care Survey, it was unclear whether overall disability among the elderly was increasing or decreasing. Manton showed that the prevalence of disability was declining in successive cohorts of elderly Medicare beneficiaries (Manton and Gu 2001). In the Manton study, as in many others, disability is defined by limitations in activities of daily living (ADLs) or the less severe limitations in instrumental activities of daily living (IADLs). The decline in the prevalence of IADL limitations was larger in both absolute and relative terms than the decline in the prevalence of ADL limitations.

These results, as David Cutler notes, have been confirmed by other investigators and soon became the conventional wisdom. The results have also changed the terms of debate in Washington, leading some legislators to argue that fears about the coming insolvency of the Medicare program are exaggerated.

There are at least two reasons to seek a better understanding of the causes of the disability decline. The first is that knowledge of the mechanisms would increase our confidence that the findings are valid and likely to continue. That is, if we knew why the apparent decline in disability has occurred, we would be in a better position to determine whether it is real and likely to continue. Despite the shift in conventional wisdom, not all the literature has confirmed declining disability. Furthermore, the disability decline reflects a disproportionate reduction in the prevalence of IADL impairments, whose causes may be different and impacts less significant than changes in the prevalence of limitations in basic ADLs. Instrumental activities of daily living are measures of higher-order functioning, such as the ability to balance a checkbook or shop without assistance. Simple technological aids, like availability of a calculator, might improve an IADL without causing any improvement in underlying health. By learning more about the mechanisms, we could obtain a more accurate impression of the magnitude and significance of the disability decline.

Second, a knowledge of mechanisms could point us toward interventions that are likely to continue or even accelerate the disability decline. A better understanding of the contributions of preventive care, medications, surgical procedures, and other interventions would suggest where we might see additional payoffs in the future. It is difficult to exaggerate the effects of such findings on the well-being of the elderly.

\section{Decomposing the Disability Decline}

Cutler approaches the disability decline by decomposing it into changes in the prevalence of disability-causing health conditions and changes in the 
probability of disability given the health condition. This is analogous to decomposing mortality rate changes into components due to changes in disease incidence and changes in case fatality rates, or mortality conditional on having the disease. This approach, if it can be applied successfully, will make it clear whether it is the avoidance of disabling diseases or their more effective treatment that deserves more credit for the disability decline.

Implementing this seemingly simple decomposition is empirically challenging. Strictly speaking, the conditions should form an exhaustive and mutually exclusive set, if they are to account for all of the changes in disability. Most people with severe disabilities have multiple chronic diseases, and without further simplifying assumptions, each combination of conditions (defined also by varying severities) should make up a single composite condition. Even with a fairly limited set of single conditions, it is infeasible to incorporate the vast number of possible combinations that people can have. Furthermore, Cutler reports that there is little clustering among combinations of conditions, so it is not possible to account for a large fraction of all combinations by limiting the analysis to a handful of the most common ones. Cutler addresses these problems by assigning each individual to the single most severe (i.e., highest probability of being associated with disability) of thirty-three conditions listed in his first table. His results show that, by and large, the incidence of health conditions rose with time, while the probability of disability, given the health conditions, declined with time. The decline in conditional disability was greater than the increase in the incidence of the health condition.

The approximation required to fit the conditions into a small number of categories can have nontrivial consequences. For example, if the mix of disease conditions aggregated into one of the thirty-three categories changed over time, it would falsely appear to be a change in conditional disability. Furthermore, changes in either the prevalence of a condition or in its conditional probability of disability may not be causal. For example, table 5.1 of Cutler's paper shows that hypertension - an asymptomatic conditionhas a disability probability of 32 percent. Hypertension can eventually cause disability by causing a stroke or heart attack, but these are separate categories in the condition list, so it is hard to see why hypertension would have an effect on disability that is independent of these conditions. Genitourinary diseases, which by themselves are rarely disabling, by this method appear to have a disability probability of 28 percent. It is very likely that both of these conditions are associated with other health conditions that are disabling. Preventing hypertension and genitourinary diseases, without preventing associated conditions that cause the disabilities, would surely result in a much smaller decrease in disability than predicted by this framework.

Alternative approaches to the disability decomposition would give different, and possibly more accurate, results. One alternative would be to 
assign each individual to a primary condition (perhaps using fewer than thirty-three) and to use a count of additional conditions to assign them to an overall category.

Changes in diagnosis over time pose another problem for any attempt to parse the effects of changes in disease prevalence and changes in outcome given disease. Improvements in screening tests, and increases in their usage, are expected to introduce "lead-time bias." Earlier diagnosis-a longer lead time-means that survival conditional on disease will be longer even if there is no effective treatment. Improvements in diagnosis are unlikely for some conditions that Cutler studies, such as hip fracture, but for others - particularly some of the cancers-innovations in testing may have increased both the prevalence of diagnosed disease and the fraction of diagnosed disease that is in its early, and less symptomatic, stages.

\section{The Relationship to Intensive Medical Care}

As Cutler notes, "The important policy question is how much of the decline in conditional disability rates is a result of medical intervention." This crucial question provides an ambitious focus for the research that he has undertaken. He estimates the relationship between changes in conditional disability and changes in intensive procedure use, noting that the results may be confounded by a number of unmeasured characteristics. Among them, and likely to be very important, are changes in the health of the patients who undergo a procedure; if procedure use diffuses from the very sick to those who are less sick and at lower risk of disability, an increase in use of the procedure may be spuriously associated with decreased disability among those who receive it.

Despite the caveats that accompany any effort of this kind, it represents an important effort to address a timely set of problems. If it is possible to find data and apply methods that are capable of establishing causal relationships, the work can provide a number of important insights. Cutler's model and others like it offer basic building blocks toward projections of medical care utilization and expenditures. More important, they can help identify productivity opportunities at the margin, such as those that result from identifying a disease whose conditional disability has changed little despite changes in prevalence over time. Finally, his results can also shed light on the appropriateness of incentives embedded in the health care system. Many disabling conditions might have effective treatments that are not covered: assistive devices, like hearing aids and visual aids, often receive limited or no coverage under conventional health insurance contracts. Not all opportunities to limit disability will arise from prevention, pharmaceuticals, "medical" devices, or intensive procedures. A reevaluation of the incentives embedded in our current approaches to health care financing might well lead to more appropriate care and better outcomes. 


\section{References}

Fries, J. F. 1980. Aging, natural death, and the compression of morbidity. New England Journal of Medicine 303:130-35.

Manton, K. G., and X. L. Gu. 2001. Changes in the prevalence of chronic disability in the United States black and nonblack population above age 65 from 1982 to 1999. Proceedings of the National Academy of Sciences 98:6354-59.

Rose, E. A., A. C. Gelijns, A. J. Moskowitz, D. F. Heitjan, L. W. Stevenson, W. Dembitsky, J. W. Long, D. D. Ascheim, A. R. Tierney, R. G. Levitan, et al. for the Randomized Evaluation of Mechanical Assistance for the Treatment of Congestive Heart Failure (REMATCH) study group. 2001. Long-term use of a left ventricular assist device for end-stage heart failure. New England Journal of Medicine 345:1435-43.

Verbrugge, L. 1984. Longer life but worsening health? Trends in health and mortality of middle-aged and older persons. Milbank Memorial Fund Quarterly 62: $475-519$. 